\title{
MMT Modified with Cationic Carbohydrates as Deliver Carrier for Praziquentel Drug
}

\author{
A.M. Youssef, H.E. Nasr, A.M. Ramadan* and W.S. Mohamed \\ Department of Polymers and Pigments, National Research \\ Centre and ${ }^{*}$ Chemistry Department, Faculty of Science, \\ Helwan University, Helwan, Cairo, Egypt.
}

\begin{abstract}
TTILIZATION of modified MMT in drug delivery is now taking a great attention due to the considerable efficiency and miscellaneous drug type. In this study, different types of cationic carbohydrate are used for MMT to optimize the best for loading and release. Tert- aminated starch (AmS) and chitosan (CS), bearing primary amino groups, are used for modification of MMT to evaluate the feasibility of loading and release of Praziquantel drug with applicable efficiency. The modified clay was characterized by XRD, TGA and SEM. The characterization via XRD and SEM demonstrates that the chitosan has greater exfoliated intercalation properties than the Tert- aminated starch. The loading efficiency of Praziquantel by modified MMT with AmS, and chitosan was $19.5 \%$ and $22.1 \%$, respectively. Drug release was studied for CS/MMT -Praziquantel hybrid and it was found that the release was directly proportional with the $\mathrm{pH}$ of the medium and reached to $82 \%$ at $\mathrm{pH} 7.4$ after $6 \mathrm{hr}$.
\end{abstract}

Keywords: MMT, Aminated starch, Chitosan, Drug delivery, Praziquantel and Characterization.

Montmorillonite clay (MMT) is a very soft phyllosilicate mineral and a member of the smectite family which is known to have cation exchange capacity ${ }^{(1-3)}$. Clay is hydrophilic due to the hydration of the interlayer alkali metal cations ${ }^{(4)}$, this leads to incompatibility of the clays with most polymers, clay must be chemically modified to be hydrophobic and to increase the interlayer distance in which drug is intercalated, through ion exchange reaction between clay minerals and organic cations (as ammonium ions or phosphonium ions) ${ }^{(5-10)}$. MMT has many applications in drug delivery system specially, in treatment of cancer ${ }^{(11-15)}$.

Chitosan, (poly-ß(1,4)-2-amino-2-deoxy-D-glucose) ${ }^{(16)}$ is a nontoxic and biocompatible cationic polysaccharide produced through the deacetylation of chitin isolated from naturally occurring crust ocean shells, is soluble in acidic solutions ( $\mathrm{pH}$ 5-5.3). The primary amino groups of chitosan provide it with special properties that are useful in pharmaceutical applications. The approach of complexing negatively charged macromolecules with chitosan during the preparation of beads suitable for use as controlled-release drug formulations has attracted substantial interest recently because this process is very simple and mild ${ }^{(17) .}$ 
There are several methods for preparation of aminated starch; where it can be prepared by reaction of ethylenediamine with dialdehyde starch, reaction of chloroethyl diethylamine with native maise starch, grafting copolymerization and ring-opening reaction of ethylene imine with cassava starch as a raw material ${ }^{(18,19)}$ dialdehyde starch or via. When inorganic clay is brought in contact with solutions which contain long-chain quaternary alkyl ammonium ion( the amino bearing modifier solution), the latter are adsorbed inbetween the clay interlayers and the hydrophilic clay is converted into organophilic one ${ }^{(20)}$. Actually, the investigation demonstrates that the amino bearing modifier intercalate with sodium montmorillonite via the ion exchange of $\mathrm{Na}^{+}$ions of MMT with $-\mathrm{NR}_{3}{ }^{+}$of the modifier ${ }^{(21)}$ hence resulting in increasing the distance between the clay layers (22)

Praziquantel, $\quad\left(\mathrm{C}_{19} \mathrm{H}_{24} \mathrm{~N}_{2} \mathrm{O}_{2}\right),(11 \mathrm{bRS})-2-($ Cyclohexylcarbonyl)-1,2,3,6,7,11bhexahydro-4H-pyrazino[2,1-a]isoquinolin-4-one was first selected for its antihelminthic action in the mid-1970s (Fig.1) and was used initially to treat veterinary cestode and trematode infections. It has been used subsequently to treat a variety of human trematode infections ${ }^{(23)}$ and is currently the drug of choice for all forms of schistosomiasis.

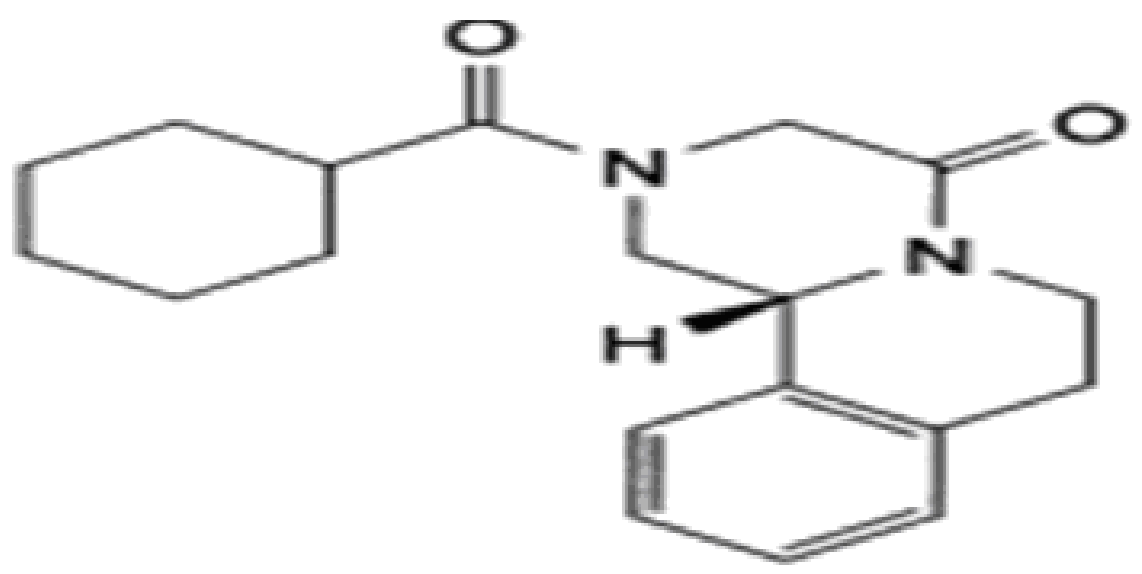

Fig. 1. Chemical structure of praziquantel drug.

As nanoclay acts as drug vehicle for controlled release of drug ${ }^{(24)}$, this work is aimed at using different types of cationic carbohydrate for modification of MMT to evaluate the feasibility of loading and release of Praziquentel drug with applicable efficiency. The modified clay was characterized by XRD, TGA, DSC and SEM as well as drug loading by U.V visible analysis and drug release profile was also studied.

Egypt. J. Chem. 55, No. 2 (2012) 


\section{Experemintal}

\section{Materials}

Chitosan (CS) with medium molecular weight $(92.700 \mathrm{~g} / \mathrm{mol})$ and deacetylation degree of $82.5 \%$ was obtained from Aldrich Chemicals - Germany. Praziquantel $\left(\mathrm{C}_{19} \mathrm{H}_{24} \mathrm{~N}_{2} \mathrm{O}_{2}\right)$ was supplied from EIPICO-10 ${ }^{\text {th }}$ of Ramadan City Egypt. Montmorillonite clay with cation exchange capacity (CEC) 90 meq per $100 \mathrm{~g}$ was supplied by Süd- Chemie-Moosburg-Germany. Glycial acetic and hydrochloric acid as well as sodium hydroxide, potassium phosphate monobasic and sodium chloride were of pure laboratory grade chemicals.

\section{Methods}

Preparation of aminated native starch

Cationization of native starch was carried out according to a method described elsewhere ${ }^{(19)}$. The obtained cationic starch was analyzed via N\% and it was found $1.54 \%$.

Modification of MMT clay by cationic carbohydrates ${ }^{(16)}$

MMT clay was modified using cationic carbohydrate expressed as AmS, (cationic starch) and chitosan according to the following procedure:

Dry weight sample was dissolved in distilled water (for cationic starch) and $2 \%$ $\mathrm{v} / \mathrm{v}$ aqueous glacial acetic acid (for chitosan) at a concentration of $2 \mathrm{wt} \%$. The prepared solution samples were subjected to centrifuging at $2000 \mathrm{rpm}$ to remove the insoluble residual material. Also, MMT was swelled in $50 \mathrm{ml}$ distilled water by magnetic stirring for $60 \mathrm{~min}$ at $30 \pm 1 \mathrm{Co}$ then added to the prepared cationic carbohydrate solution (CC) with CC /MMT wt ratio of 1/1, 1/2 and 2/1, followed by stirring for $4 \mathrm{hr}$ under different temperature (40,50, 60 and $70^{\circ} \mathrm{C}$ ). Then, CC-modified MMT samples (CC/MMT) were filtered from its solutions and dried under vacuum at $70^{\circ} \mathrm{C}$ for $48 \mathrm{hr}$.

\section{Preparation of drug-loaded cationic carbohydrate modified MMT clay ${ }^{(25)}$}

Praziquantel was selected as a model drug. The procedure for preparing the praziquantel-loaded cationic carbohydrate modified MMT clay was typically as follows: different weights of the drug $(0.05,0.1,0.15$ and $0.2 \mathrm{gm})$ were dissolved with $\mathrm{CC} / \mathrm{MMT}$ samples which was prepared under the optimum conditions of temperature and concentrations. The mixture was subjected to a magnetic stirring at different reaction temperatures $\left(30,40,50\right.$ and $\left.60^{\circ} \mathrm{C}\right)$ for different times $(0.5,1,2$ and $4 \mathrm{hr})$ to optimize drug loading onto CC/MMT. 

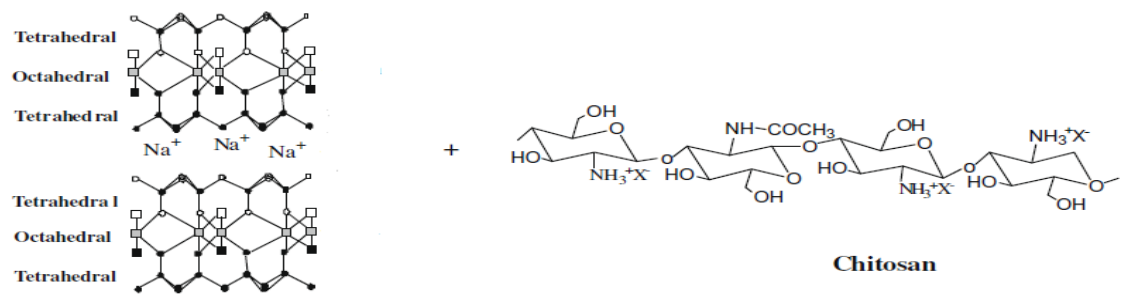

Chitosan

$\mathbf{n N a} \mathbf{a}^{+}$

Tetrahedral

Octahedral

Tetrahedral

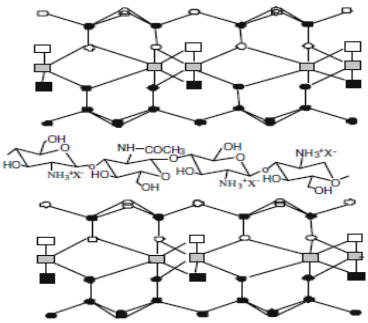

Fig. 2. Schematic illustration of intercalation of chitosan in the interlayer space between the MMT clay.

In-vitro release of Praziquantel from drug loaded cationic carbohydrate modified MMT clay ${ }^{(26)}$

In-vitro release of Praziquantel from CC / MMT- Praziquantel hybrid was carried in phosphate buffered saline media at $\mathrm{pH} 7.4$ and simulated gastric fluid at $\mathrm{pH} 1.2$ using two different simulated fluid buffer solutions. The simulated gastric fluid having $\mathrm{pH} 1.2$ was prepared by mixing $250 \mathrm{ml}$ of $0.2 \mathrm{M} \mathrm{HCl}$ with $147 \mathrm{ml}$ of $0.2 \mathrm{M} \mathrm{KCl}$ while the simulated intestinal fluid having $\mathrm{pH} 7.4$ was prepared by mixing $250 \mathrm{ml}$ of $0.1 \mathrm{M} \mathrm{KH}_{2} \mathrm{PO}_{4}$ with $195.5 \mathrm{ml}$ of $0.1 \mathrm{M} \mathrm{NaOH}$.

150mg of CC / MMT- Praziquantel hybrid in 5ml of buffer solution was taken in a round flask containing $300 \mathrm{ml}$ dissolution medium, which was incubated in a constant temperature shaker water bath at $37 \pm 0.5 \circ \mathrm{C}$. The flask was closed to prevent the evaporation losses from the dissolution medium. The shaking frequency was kept at $100 \mathrm{rpm} .5 \mathrm{ml}$ of sample was withdrawn at regular time intervals and the same volume was replaced with a fresh dissolution medium. Samples were analyzed for Verapamil hydrochloride content by UV spectrophotometer at $\lambda-\max =210 \mathrm{~nm}$. These studies were performed in triplicate for each sample and the average values were used in data analysis.

\section{Characterization}

X-ray diffraction (XRD) measurements were performed using a Philips powder-Diffractogram PW 1050 with ADM software and with Ni-filtered $\mathrm{Cu} \mathrm{K}$ radiation. The accelerating voltage was $40 \mathrm{KV}$, and the current was $30 \mathrm{~mA}$. The 
morphology and fracture surface of the composites were examined by Scanning electron microscope (SEM) analysis using Zeiss,DSM 962 microscope. UV-vis absorbance of Praziquantel solutions was measured using UV-vis spectrophotometer (Cary 500, Varian) equipped with a quartz cell having a path length of $1 \mathrm{~cm}$ at $\lambda-\max =210 \mathrm{~nm}$

\section{Results and Discusions}

\section{Characterization of modified MMT clay}

$X$-ray diffraction (XRD)

MMT clay nanoparticles were modified by different MMT/ cationic carbohydrates (Chitosan and Aminated starch) ratio at different temperatures. The basal spacing (d001) values of these samples are calculated from the peak position using Bragg,s equation as follows:

$$
\mathrm{n} \lambda=2 \mathrm{~d} \sin \theta
$$

Figures 3 and 4 illustrate the XRD patterns of MMT and different CC/ MMT ratios at $50^{\circ} \mathrm{C}$. From the figures it is clear that, the XRD pattern of the MMT shows a reflection peak at about $2 \Theta=10.6$, corresponding to a basal spacing ( $d$ space) of $7.92 \mathrm{~nm}$. The data for $2 \Theta$ and d-spacing for the studied CC samples, CS and/or Am-St, are listed in Table 1. The data shows many interesting points: (i) the diffraction peaks of all modified MMT clay samples are shifted to smaller angels compared with the pure MMT, this was observed regardless of the type of CC used, which indicates that MMT clay was successfully intercalated with $\mathrm{CC}^{(27-28)}$ (ii) increasing $\mathrm{CS}$ contents in the CS/MMT ratio from 1:2 to $2: 1$ was accompanied by gradual decreasing of $2 \Theta$ from $8.4^{\circ}$ to $7.3^{\circ}$ while $\mathrm{d}$ space was increased from 9.97 to 11.46 , reflecting the increment of CEC as well as the interlayer spacing and the composite structure of CS/MMT composites ${ }^{(29)}$; (iii) increasing Am-St contents from 1:2 to 1:1 was followed by remarked increase of d space from 9.3 to 10.46 then it became constant after further Am-St increment; (iv) at constant CC/MMT ratio (1:1), $\mathrm{d}$ space for CS as modifying substrate is relatively higher than Am-St, indicating greater CEC for the former than the later. These findings could be recognized due to the difference between the two studied CC as natural polymeric materials with respect to $\mathrm{N} \%$, molecular weight, viscosity and chain branching. Native chitosan is characterized by its higher abundant nitrogen content $(\sim 7.0 \%)$ and greater molecular weight and viscosity than used hydrolysed aminated starch. 


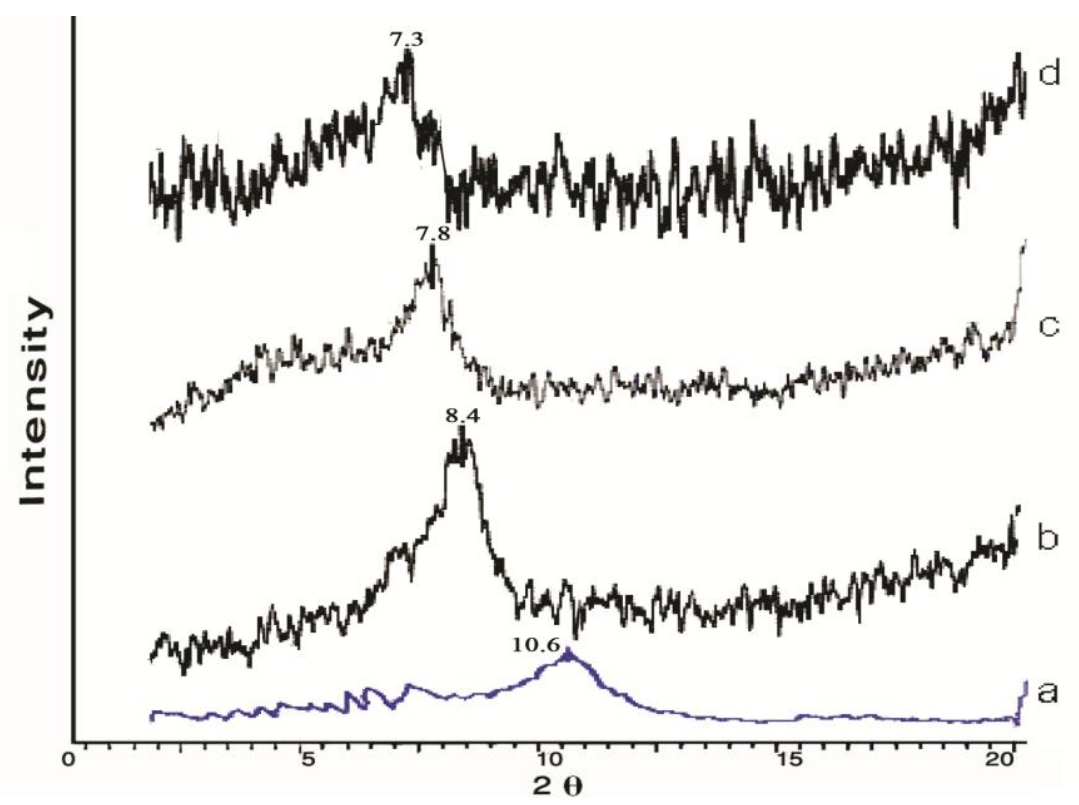

Fig. 3. X-ray diffraction patterns for (a) neat-MMT, MMT modified by chitosan at (CS/MMT) ratios of (b) 1:2, (c) 1:1, and (d)2:1 .

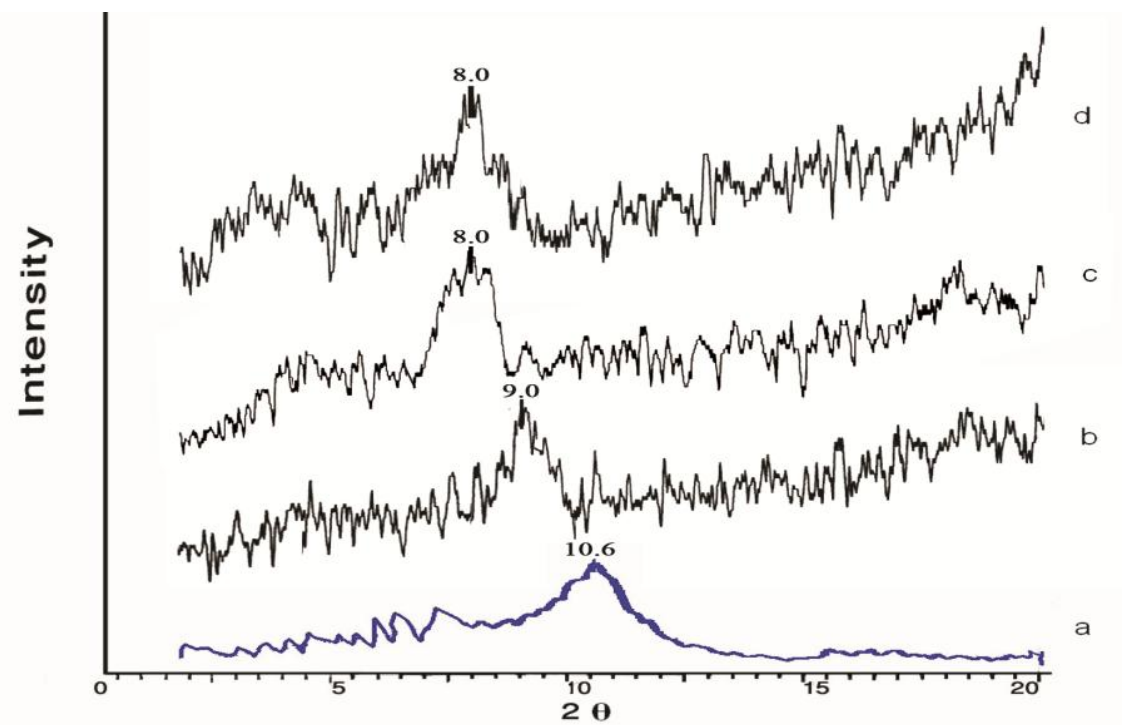

Fig. 4. X-ray diffraction patterns for (a) neat-MMT, MMT modified by aminated starch at (AmS/MMT) ratios of (b) 1:2, (c) 1:1, and (d)2:1.

Egypt. J. Chem. 55, No. 2 (2012) 
Figures 5 and 6 show the XRD patterns for MMT modified by CC using CC/MMT ratio 2:1 at different temperatures from 40 to $70^{\circ} \mathrm{C}$. The obtained $2 \Theta$ and $\mathrm{d}$ space are listed in Table 1. It is evident that the diffraction peaks of all modified MMT clay samples are shifted to smaller angels which means an increase in the $\mathrm{d}$ spacing with increasing temperature till $60^{\circ} \mathrm{C}$ implying the occurrence of a gallery widening and the transformation into a less ordered intercalated structure and a less correlation in the direction perpendicular to the MMT layers ${ }^{(30)}$, this was observed irrespective of CC type used. Moreover, for $\mathrm{CS} / \mathrm{MMt}$ composite, at higher temperature than $60 \mathrm{oC}$, more polymer molecules or segments penetrate into the galleries to widen the gallery, broaden the distribution of the gallery height and possibly exfoliation of individual layers occurs simultaneously. Similar annealing temperature effect on the structure of polymer/organo-silicate nanocomposites has been reported by Galgali et al. ${ }^{(31)}$ and Vaia and Giannelis ${ }^{(32)}$.

From the figures and the data listed in Table 1, it is also obvious that, after 60 ${ }^{\circ} \mathrm{C}$, the $2 \Theta$ value increases and the $\mathrm{d}$ value decreases with increasing the temperature. This shows that the interplanar spacing in the hexagonal structures decreases with increasing heat treatment temperature, suggesting that the interplanar spacing can be controlled by temperature ${ }^{(33)}$.

For Am/MMT composite, it is also obvious that, the locations of the diffraction peaks are essentially the same when the modification temperature increased from 60 to $70{ }^{\circ} \mathrm{C}$, implying that there is no change in the composite structure when the temperature changed from 60 to $70{ }^{\circ} \mathrm{C}^{(34)}$.

Generally, it can be concluded that CS / MMT nanocomposites have bigger basal spacing compared with AmS / MMT composites when using the same weight ratio of clay content and under the same modification temperature implying that under the same conditions chitosan has more ability for penetration between MMT layers than aminated starch. 


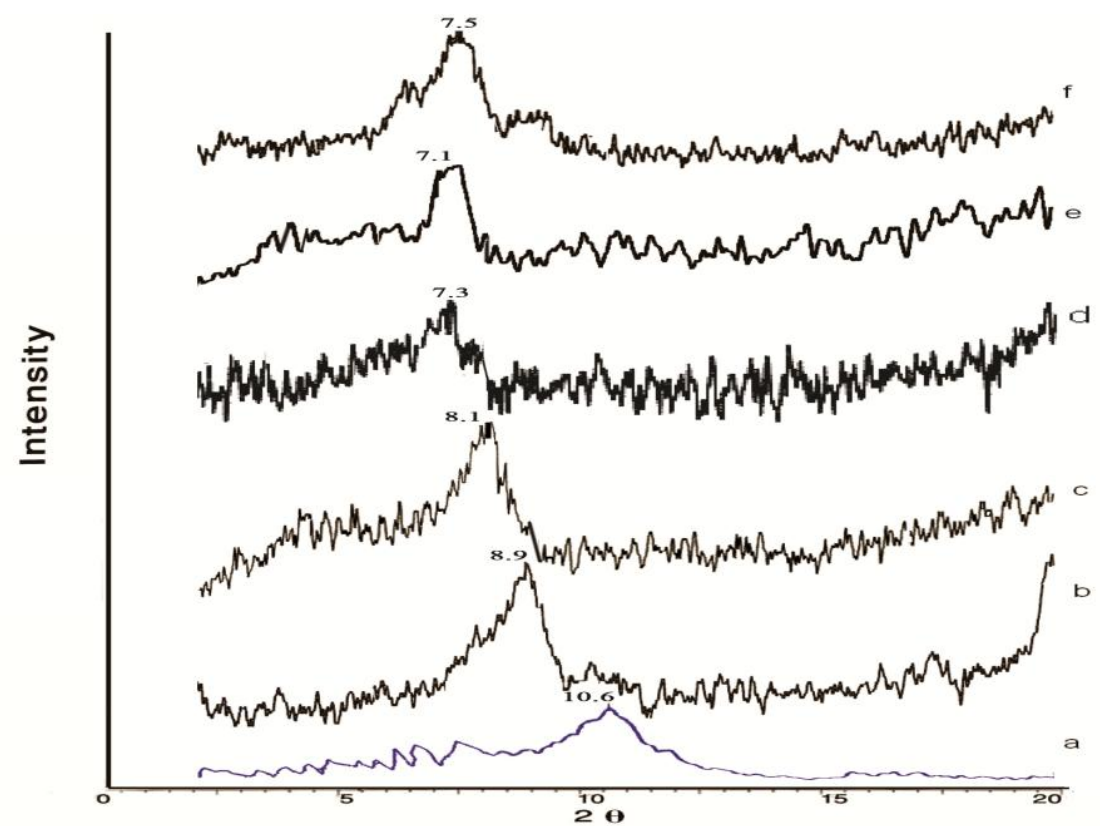

Fig. 5. X-ray diffraction patterns for (a)neat MMT, MMT modified by chitosan at temperatures of $\quad$ (b) $30^{\circ} \mathrm{C},\left(\right.$ c) $400^{\circ} \mathrm{C},(d) 50^{\circ} \mathrm{C}$. (e) $60^{\circ} \mathrm{C}$ and $(f) 70^{\circ} \mathrm{C}$.

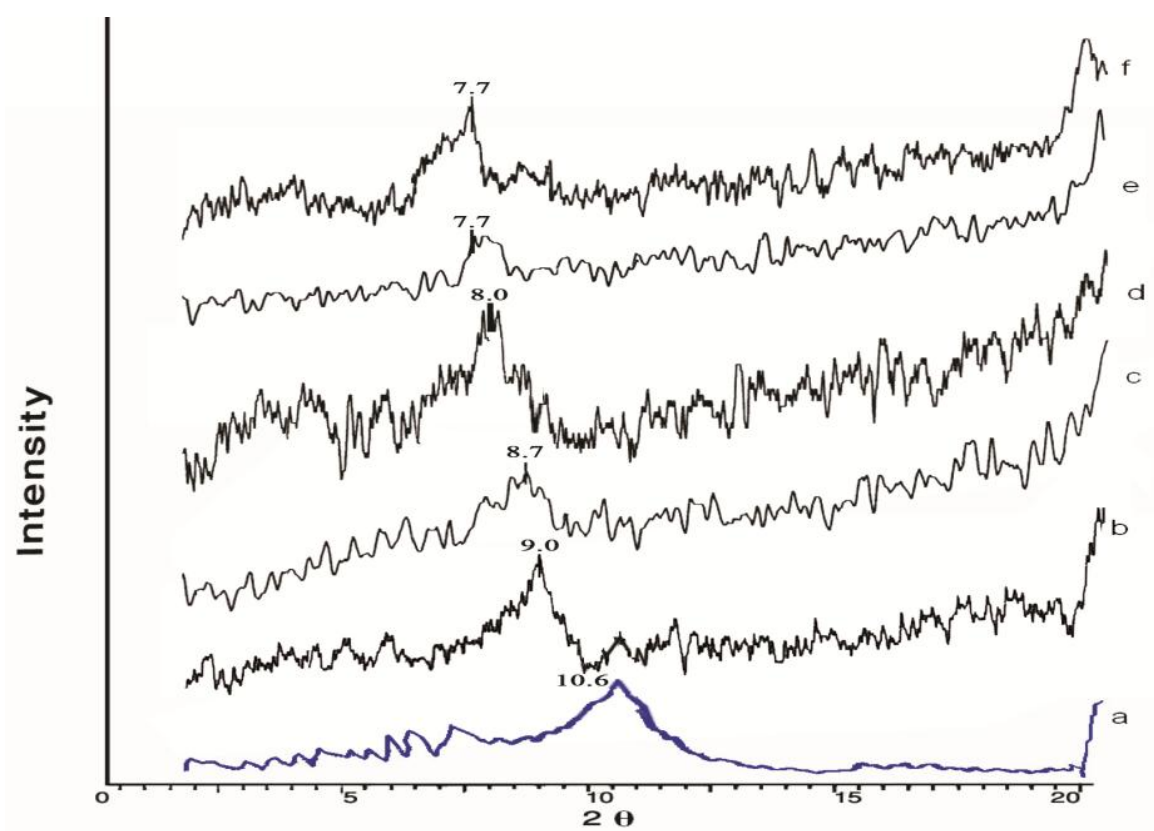

Fig. 6. X-ray diffraction patterns for (a)neat MMT, MMT modified by aminated starch at temperatures of (b) $30^{\circ} \mathrm{C},(\mathrm{c}) 40^{\circ} \mathrm{C},(\mathrm{d}) 50^{\circ} \mathrm{C} .(\mathrm{e}) 60^{\circ} \mathrm{C}$ and $(\mathrm{f}) 70^{\circ} \mathrm{C}$.

Egypt. J. Chem. 55, No. 2 (2012) 
TABLE 1. XRD data obtained for pristine MMT and cationic carbohydrates / MMT hybrids .

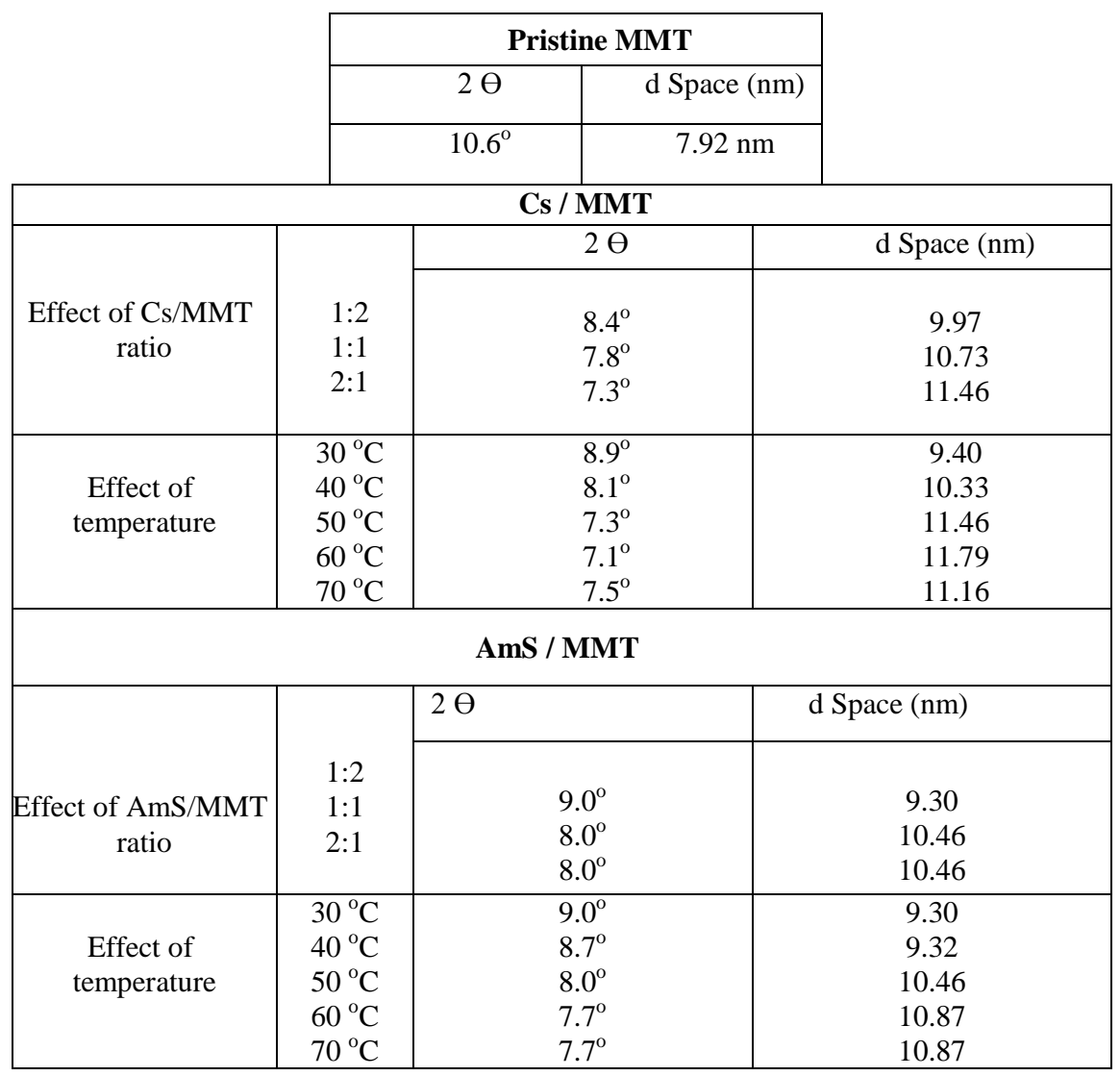

Scanning Electron Microscope (SEM)

The examination of the surface of the prepared samples was investigated by SEM as shown in Fig. 7 which displays SEM of pristine MMT and MMT modified by natural polymer prepared under optimizing conditions. The SEM images indicate that chitosan and aminated starch are homogenously with MMT clay to produce clay/polymer nanocomposites where MMT clay is poorly dispersed in case of aminated starch while it is homogenously dispersed in case of chitosan. This finding was in agreement with that obtained with XRD analysis of the two studied composites. 


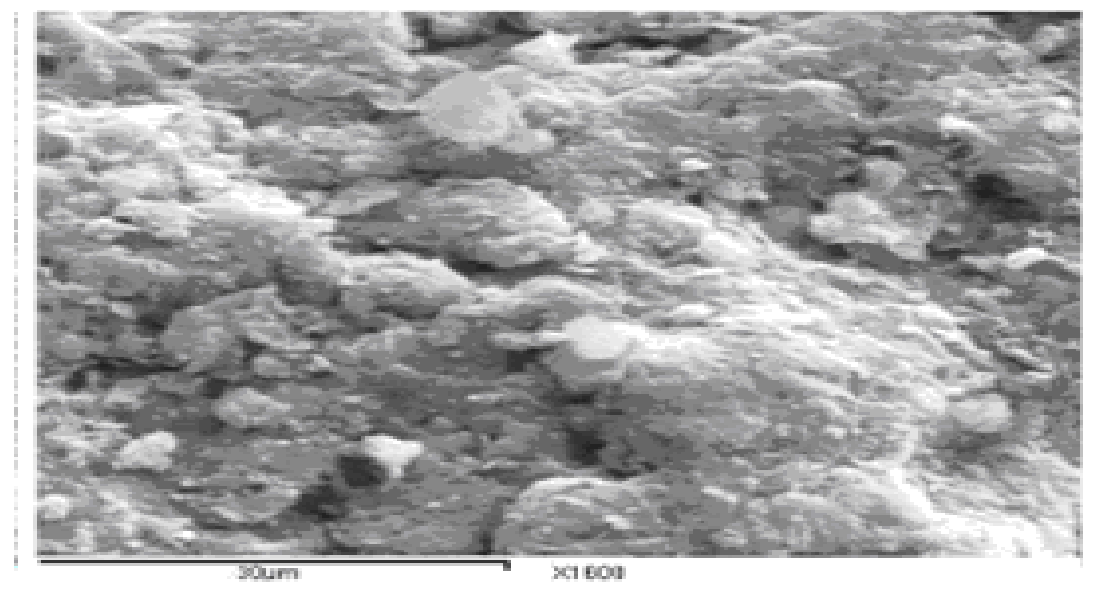

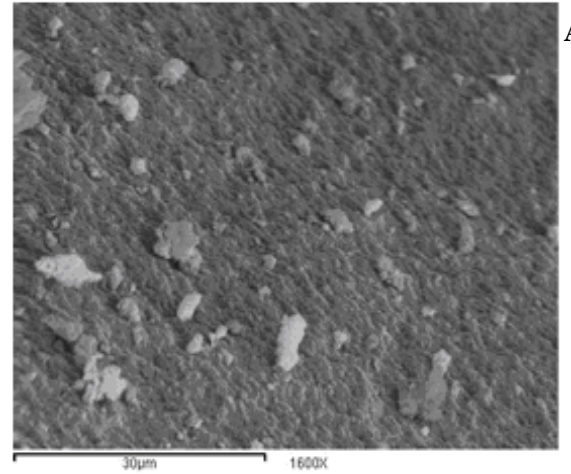

B

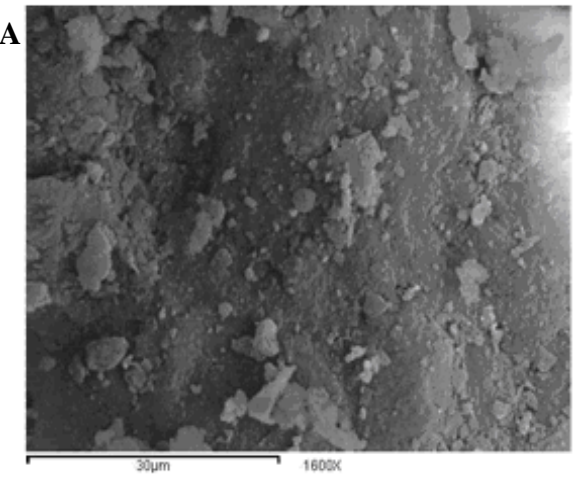

C

Fig. 7 . SEM for A) pristine MMT clay, B) MMT clay modified by chitosan and C) MMT clay modified by aminated starch.

Thermal gravimetric analysis (TGA)

The thermal stability of pristine MMT clay and the MMT clay modified by chitosan (CS/MMT) and aminated starch (AmS/MMT) was determined by measuring the thermogravimetric analysis (TGA) within the temperature range $50-600{ }^{\circ} \mathrm{C}$, as shown in Fig. 8. In general, it is clear that all weight loss temperatures for the MMT clay modified by natural polymer samples are higher than those of the pristine MMT clay, which can be attributed to the restriction of the motion of the polymer organic chains attached to MMT clay ${ }^{(35)}$.

Table 2 shows a comparison in the weight loss $\%$ in different temperatures between CS/MMT and AmS/MMT prepared under the same conditions of concentration ratio and temperature. From the results listed in this table, it can be concluded that CS/MMT has more thermal resistance compared with AmS/MMT where AmS/MMT loses the weight more rapidly and at lower temperature than CS/MMT which can be explained by the increase in homogenous dispersion between Egypt. J. Chem. 55, No. 2 (2012) 
the MMT clay layers and the natural polymer in case of chitosan more than in case of aminated starch, which lead to increase the thermal stability ${ }^{(36)}$.

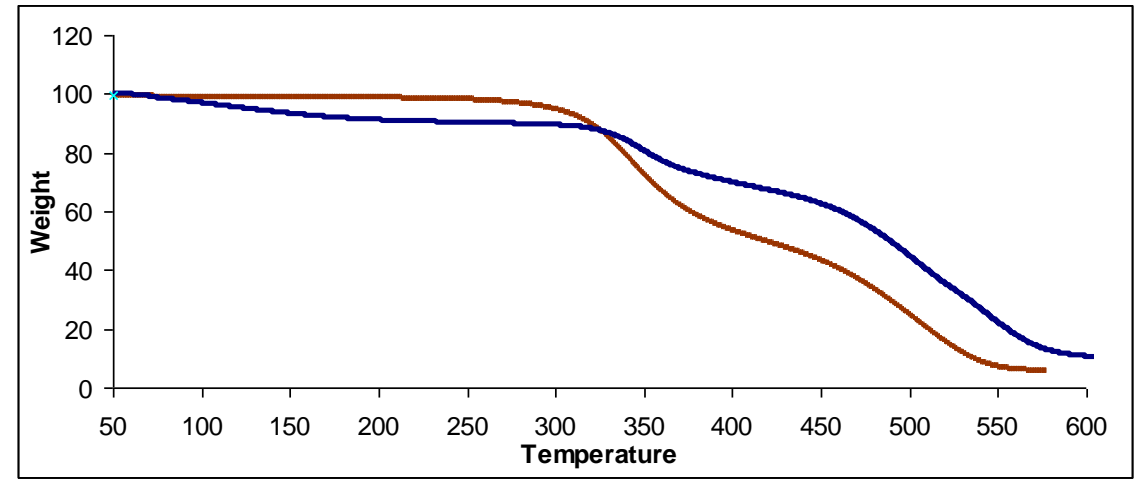

Fig. 8. TGA of A) Cs / MMT and, B) AmS /MMT.

TABLE 2. Comparison in the weight loss \% between CS/MMT and AmS/MMT prepared under the same conditions of concentration ratio and temperature.

\begin{tabular}{|c|c|c|}
\hline \multirow{2}{*}{ Temperature } & \multicolumn{2}{|c|}{ Weight loss \% } \\
\cline { 2 - 3 } & CS / MMT & AmS / MMT \\
\hline 350 & 19.24 & 27.6 \\
375 & 36.3 & 39.5 \\
400 & 30.0 & 47.7 \\
425 & 33.3 & 52.4 \\
450 & 37.2 & 56.7 \\
475 & 44.3 & 64.5 \\
500 & 55.4 & 75.3 \\
525 & 66.5 & 86.5 \\
550 & 78.0 & 92.75 \\
575 & 86.3 & 94.2 \\
600 & 89.2 & -- \\
\hline
\end{tabular}

Preparation of drug-loaded cationic carbohydrate modified MMT clay

Effect of initial drug weight

The effect of the initial drug weight was studied at optimum cationic carbohydrate / MMT ratio and $50{ }^{\circ} \mathrm{C}$ drug loading temperature for $1 \mathrm{hr}$. The loaded percentage of Praziquantel drug is effected by the drug initial weight as shown in Fig. 9 where as the initial Praziquantel drug weight increased, the amount of loaded drug was also increased which may be due to the increasing of the active gradients at the initial stage where it reached maximum drug loaded after $0.15 \mathrm{gm}$ of Praziquantel drug. From the figure it can be concluded that about $22 \%$ of the Praziquantel drug was loaded into CS/MMT hybrid and about $19 \%$ of the drug was loaded into AmS/MMT hybrid. 


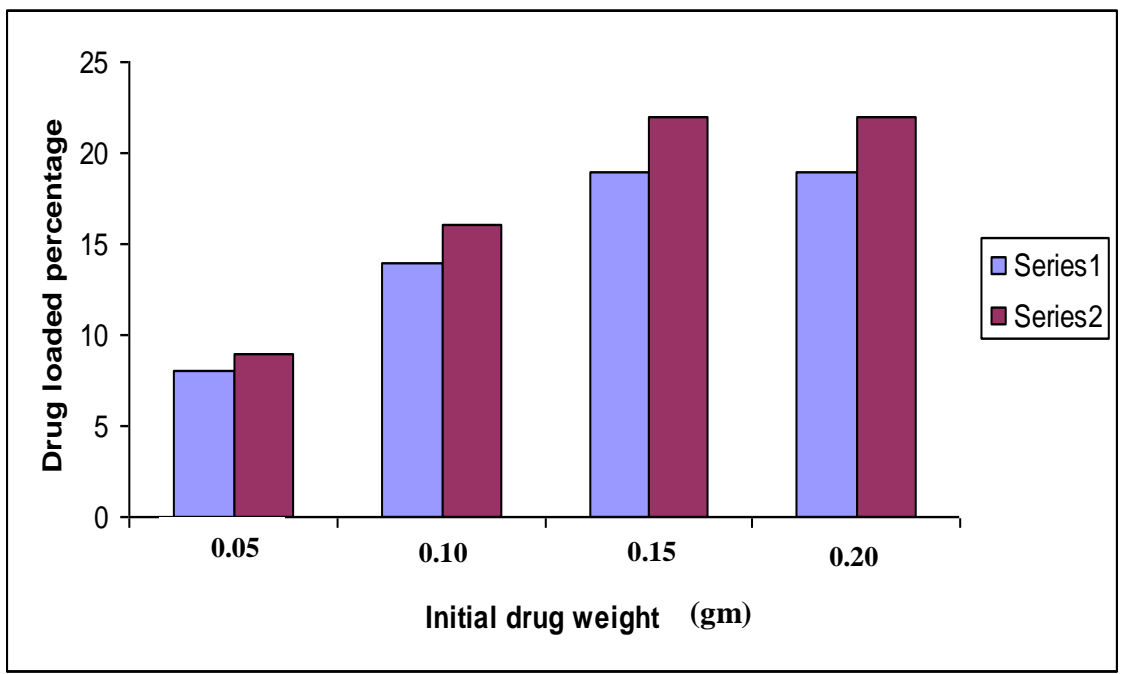

Fig. 9. Effect of the initial drug weight on the drug loaded percentage for 1 (AmS/MMT and 2) CS/MMT hybrids .

Effect of drug loading temperature

The Praziquantel drug loading performance was studied using optimum cationic carbohydrate / MMT ratio and initial drug weight $0.15 \mathrm{gm}$ at different loading temperatures $\left(30-60^{\circ} \mathrm{C}\right)$.

Figure 10 shows the relation between the drug loading temperature and the drug loaded percentage. From the figure, it is clear that, the Praziquantel drug loading percentage increased as the loading temperature increased and reached maximum at $50{ }^{\circ} \mathrm{C}$.

The increasing of the drug loading percentage with increasing loading temperature may be due to at high temperature, the efficiency of the drug penetration into cationic carbohydrate / MMT hybrids increased.

\section{Effect of drug loading time}

The praziquantel drug loading into cationic carbohydrate / MMT hybrid was studied at different time $(0.5-4$ hours $)$, constant loading temperature $\left(50{ }^{\circ} \mathrm{C}\right)$, constant initial drug weight $(0.15 \mathrm{gm})$ and optimum cationic carbohydrate / MMT ratio.

Figure 11 shows the relation between the drug loading time and drug loading percentage. From this figure, it can be seen that, the drug loading is very rapidly at first interval and reached maximum at $1 \mathrm{hr}$ then it remains constant up to $4 \mathrm{hr}$.

The loading time $1 \mathrm{hr}$ was taken as the best condition to avoid the partial drug intercalation in the subsequent experiments ${ }^{(37)}$.

Egypt. J. Chem. 55, No. 2 (2012) 


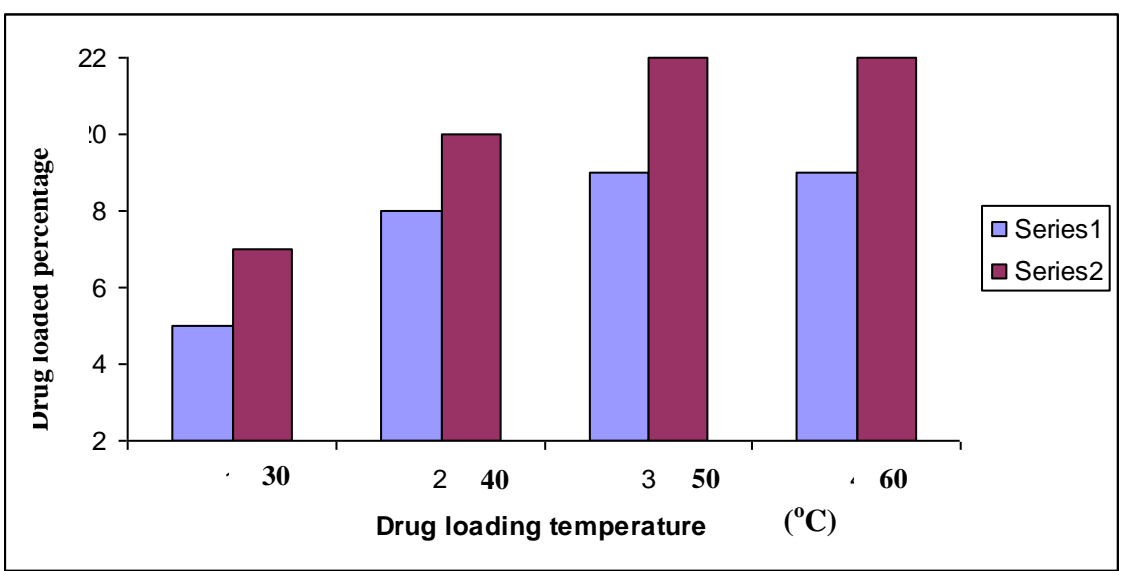

Fig. 10. Effect of the drug loading temperature on the drug loaded percentage for 1) AmS/MMT and 2) CS/MMT hybrids

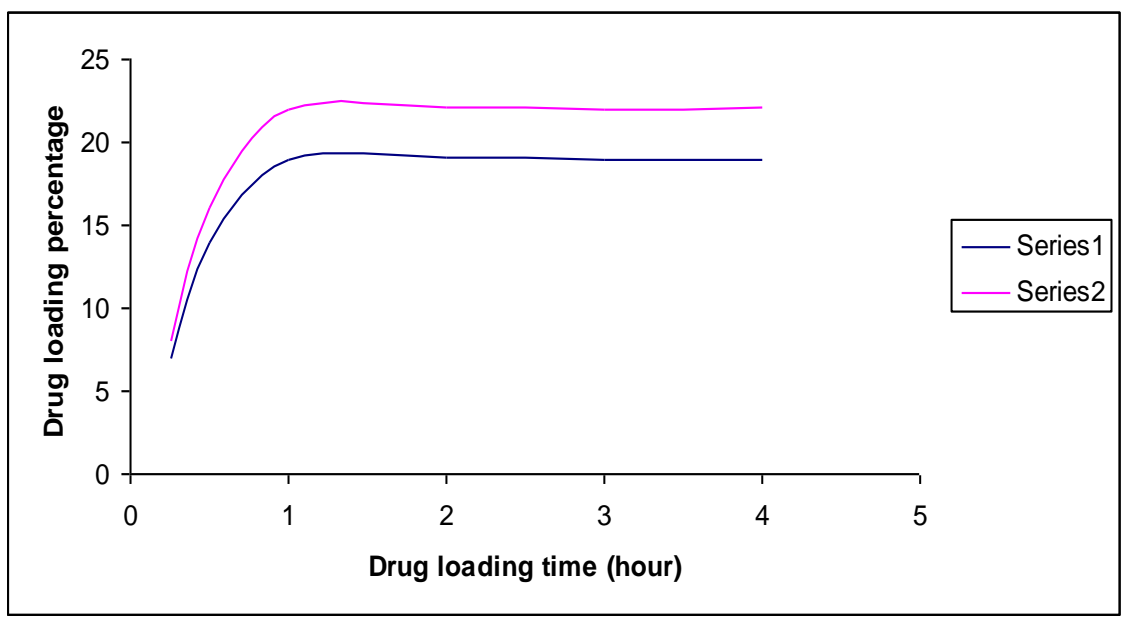

Fig. 11. Effect of the drug loading time on the drug loaded percentage for 1) $\mathrm{AmS} / \mathrm{MMT}$ and 2) CS/MMT hybrids .

The data illustrated in the figures (9-11) shows that, in all factors studied (initial drug weight, loading temperature and loading time), the percentage of drug loaded in case of Cs/MMT hybrid is more than that in case of AmS/MMT hybrid which is compatible with the XRD patterns in this work.

In-vitro release profile

The drug release rate was carried out dependant on the $\mathrm{pH}$ value of the medium by suspending the CS/MMT-Praziquantel hybrid in a simulated gastric fluid ( $\mathrm{pH} 1.2)$ and intestinal fluid $(\mathrm{pH}$ 7.4) under continuous shaking at $37 \pm 0.5 \circ \mathrm{C}$. 
Praziquantel drug release from Cs/MMT hybrid was measured at 0.5 hour of time intervals by measuring the absorbance at $\lambda-\max =210 \mathrm{~nm}$ and the resulted date was illustrated in Fig. 12.

From the figure it is clear that, the drug release rate was dependant on the $\mathrm{pH}$ of the medium and increased at higher $\mathrm{pH}$ where the release process may be interpreted based on the ion exchange process between the loaded drug and the alkali metal ions of the buffer ${ }^{(38)}$. From the figure, it is also concluded that the initially praziquantel release was fast where about $48 \%$ of the loaded drug was released in the first 4 hours using simulated gastric fluid ( $\mathrm{pH}$ 1.2) while the release using intestinal fluid ( $\mathrm{pH} 7.4$ ) continued up to $6 \mathrm{hr}$ and reached to about $82 \%$ from the loaded Verapamil drug.

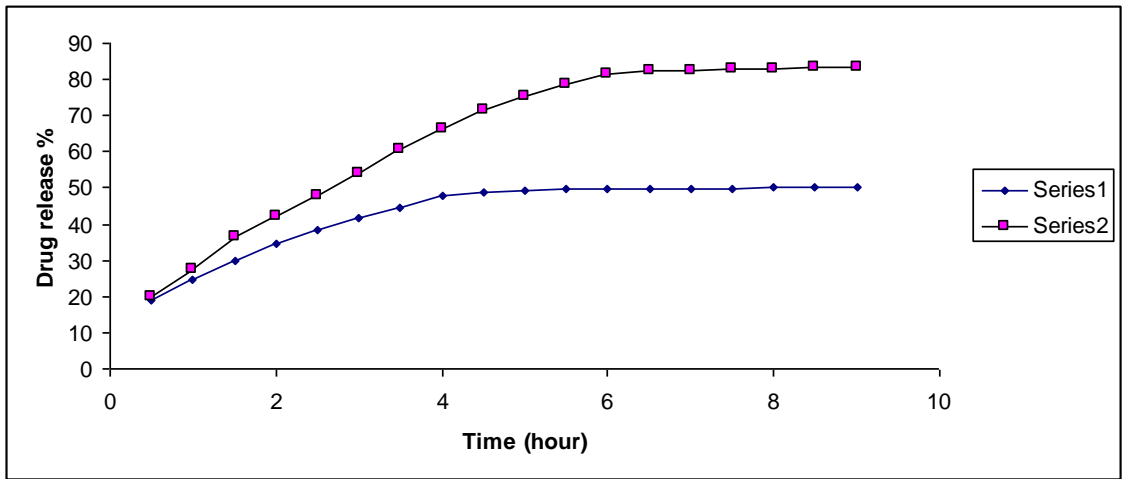

Fig. 12 . Release profile of Praziquantel drug from Cs/MMT Praziquantel hybrid in 1) simulated gastric fluid ( $\mathrm{pH}$ 1.2) and 2) simulated intestinal fluid (pH 7.4) at $37 \circ \mathrm{C}$.

From the figure it is also clear that, the release amount of the praziquantel drug did not reach $100 \%$ in both $\mathrm{pH} 1.2$ and 7.4, this is probably due to the characteristic of ion-exchange reaction, i.e. this is an equilibrium process, and the interlayer cations cannot be exchanged completely. Moreover, the existence of electrostatic interactions between the protonated amino groups of the Praziquantel cations and the anionic charges at surface of the CS/MMT hybrid may lead to incomplete release ${ }^{(13)}$.

\section{Conclusion}

MMT clay with interlayer spacing $7.92 \mathrm{~nm}$ and CEC $90 \mathrm{mg} / 100 \mathrm{gm}$ was successfully modified with two types of cationic carbohydrates which are chitosan and aminated starch at different temperatures using different natural polymer / MMT ratios. Cs/MMT hybrid displays the biggest interlayer spacing of $11.79 \mathrm{~nm}$ when using $\mathrm{Cs} / \mathrm{MMT}$ ratio of $2: 1$ at $50{ }^{\circ} \mathrm{C}$. Praziquantel drug was successfully loaded into natural polymer/MMT hybrids under several conditions as initial drug weight, loading temperature and loading time where the drug loading was proved by SEM and TGA, where in all factors studied, the

Egypt. J. Chem. 55, No. 2 (2012) 
percentage of drug loading in case of Cs/MMT hybrid was more than that in case of AmS/MMT hybrid and reached to $22.1 \%$ in $1 \mathrm{hr}$ at $50{ }^{\circ} \mathrm{C}$ and using $0.15 \mathrm{gm}$ initial drug weight. The Praziquantel drug release from Cs/MMT-Praziquantel hybrid was studied and the results showed that the release was directly proportional with the $\mathrm{pH}$ of the medium and reached to $82 \%$ after $6 \mathrm{hr}$.

\section{References}

1. Effenberger, F., Schweizer, M. and Mohamed, W.S., J. Appl. Polym. Sci. 112, 1572 (2009).

2. Effenberger, F., Schweizer, M. and Mohamed, W.S., J. Appl. Polym. Sci. 113, 492 (2009).

3. Effenberger, F., Schweizer, M. and Mohamed, W.S., Polym-Plastics Technol and Eng. 49, 525 (2010).

4. Nasr, H.E. and Mohamed, W.S., J. Am. Sci. 6, 10 (2010).

5. Theng, B.K.G., John Wiley \& Sons: New York (1974).

6. Giannelis, E.P., Adv.Mater. 8, 29 (1996).

7. Magauran, E.D., Kieke, M.D., Reichert, W.W. and Chiavoni, A., NGLI Spokeman, 50, 453 (1987).

8. Mardis, W.S., J. Am.Oil Chemists Soc. 61, 382 (1984).

9. Kornmann, X., Berglund, L.A., Sterte, J. and Giannelis, E.P., Polym. Eng. \& Sci. 38, 1351 (1998).

10. Isoda, K., Kuroda, K. and Ogawa, M., Chemistry of Materials,12, 1702 (2000).

11. Zheng, J.P., Luan, L., Wang, H.Y., Xi, L.F. and Yao, K.D., Appl. Clay Sci. 36, 297 (2007).

12. Lin, F.H., Lee, Y.H., Jian, C.H., Wong, J.M. and Wang, C.Y.A., Biomaterials, 23, 1981 (2002).

13. Nunes, C.D., Vaz, P.D., Fernandes, A.C., Ferreira, P., Roma, C.C. and Calhorda, M.J., Eur. J. Pharm. Biopharm. 66, 357 (2007).

14. Dong,Y. and Feng, S.S., Biomaterials, 26, 6068 (2005).

15. Bonina, F.P., Giannossi, M.L., Medici, L., Puglia, C., Summa, V. and Tateo, F., Appl. Clay Sci. 36, 77 (2007).

16. Wang, S.F., Shen, L., Tong, Y.J., Chen, L., Phang, I.Y., Lim, P.Q. and Liu, T.X., Polym. Degrad. and Stabil. 90, 131 (2005).

17. Kumar, M.N., Polym. 46, 1 (2000). 
18. Dong, A., Xie, J., Wang, W., Yu, L., Liu, Q. and Yin, Y., J.Hazard Mater. 181, 448 (2010).

19. El-Alfy, E.A., Samaha, S.H. and Tera, F.M., Starch/Starke, 43, 235 (1991).

20. Malucelli, A.G., Ronchetti, S., Lak, N., Priola, A., Dintcheva, N.T. and La Mantia, F.P., Euro. Polym. Journal, 43, 328 (2007).

21. Zhao, F., Bao, X., McLauchlin, A.R., Gu, J., Wan, C. and Kandasubramanian, B. Appl. Clay Sci. 47, 249 (2010).

22. Adrian Botana, Mariana Mollo, Patricia Eisenberg, and Rosa M. Torres Sanchez, Appl. Clay Sci. 47, 263 (2010).

23. Ronketti, F.A., Ramana, V., Chao-Ming, X., Pica-Mattoccia, L., Cioli, D. and Todd, M.H., Bioorganic \& Medicinal Chemistry Letters, 17, 4154 (2007).

24. Patel, H.A., Somani, R.S., Bajaj, H.C. and Jasra, R.V., Bull. Mater. Sci. 29, 133 (2006).

25. Ghanshyam, V. J. , Bhavesh, D., Kevadiya, H.A.P., Hari C. B. and Raksh, V. J., Int. J. Pharm. 374, 53(2009).

26. Youmei, C., Anning, Z., Bo, L. and Jun, L., App. Clay Sci. 49, 108 (2010).

27. Samuels, R.J., J. Polym, Sci Polym Phys. 19, 1081 (1981).

28. Ogawa, K., Yui, T. and Miya, M., Biosci Biothechnol Biochem. 56, 858 (1992).

29. Peter, C., Zhen, W. and Thomas, P., Appl Clay Sci.15, 11 (1999).

30. Yang, K. and Hu, C., European Polymer Journal, 42, 402 (2006).

31. Galgali, G., Ramesh, C. and Lele, A., Macromolecules, 34, 852 (2001).

32. Vaia, R.A. and Giannelis, E.P., Macromolecules (30) ,8000 (1997).

33. Gao, P., Bai, Y., Lin, S., Guo, W. and Xiao, H., Ceramics International, 34, 1975 (2008).

34. Shibata, H., Chiba, Y., Kineri, T., Matsumoto, M. and Nishio, K. Colloids and Surfaces A: Physicochem. Eng. Aspects, 358,1(2010).

35. Ding, Y. Guo, C. Dong, J. and Wang, Z., J. Appl. Polym. Sci. 102, 4314 (2006).

36. Gunister, E. Pestreli, D. Cuneyt, H. Atıcı, O. and Gungor, N., Carbohydrate Polymers, 67, 358 (2007).

37. Ghanshyam, V.J., Bhavesh, D., Kevadiya, H.A.P., Hari, C.B. and Raksh, V.J., Int. J. Pharm. 374, 53(2009).

Egypt. J. Chem. 55, No. 2 (2012) 
38. Zhang, H., Zou, K., Guo. S. and Duan. X.J., Solid State Chem. 179, 1792 (2006).

(Received: $21 / 2 / 2012$;

\section{المونتموريلونيث المعدل بالكربوهيدرات الكاتيونية كموصل حامل

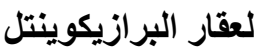 \\ أسماء محمد يوسف ، هناء السيد نصر، أحمد محمد رمضان *و وائل صبرى

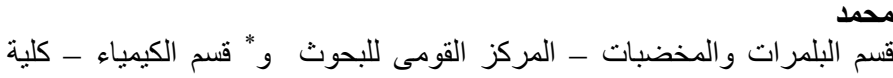

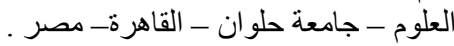

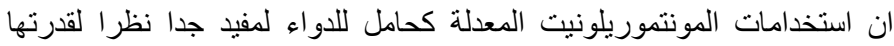

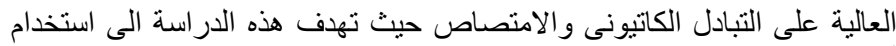

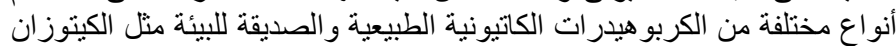

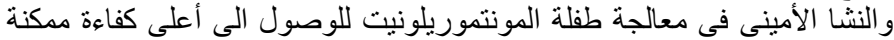

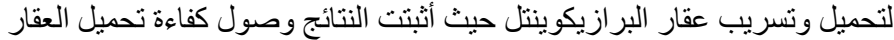

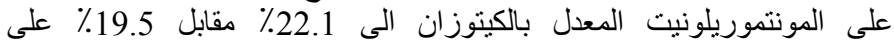

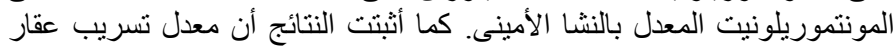

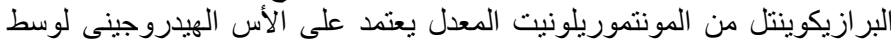

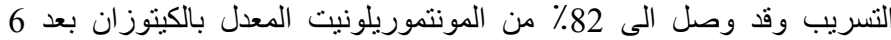

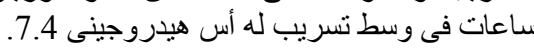

وقد تم توصيف المونتموريلونيت المعدل باستخدام أشعة الحيود السينية

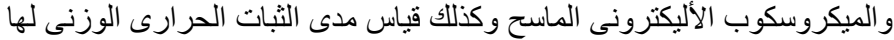

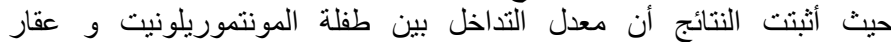

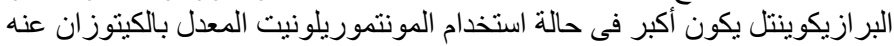

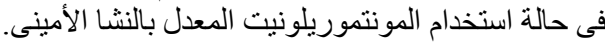

